\title{
28 Research Square \\ Primary Giant Cell Tumor of the Axis: a Case Report
}

\section{Peng Wang}

Weihai Municipal Hospital

Chunhao Song

Weihai Wendeng District People's Hospital

\section{Cong Chen}

Weihai Municipal Hospital

Bo Liu

Weihai Municipal Hospital

Jun Jia

Weihai Municipal Hospital

Xiangquan Chu ( $\nabla$ bonechuxq@126.com )

The First Affiliated Hospital of Shandong First Medical University

\section{Case Report}

Keywords: giant cell tumor, the axis, diagnosis, treatment, case report

Posted Date: January 11th, 2021

DOI: https://doi.org/10.21203/rs.3.rs-141431/v1

License: (c) (i) This work is licensed under a Creative Commons Attribution 4.0 International License.

Read Full License 


\section{Abstract}

Background: Primary giant cell tumor of the axis is a rare. The authors reported a case of a primary giant cell tumor of the axis revealed by cervical pain, and discussed the diagnosis and treatment of giant cell tumor.

Case presentation: The patient presented to our clinic with neck pain and unstable gait. X-ray, computed tomography and magnetic resonance imaging showed osteolysis of the body and vertebral arch of the axis. Histologic evaluation gave a conclusion of a giant tumor, grade II. Spondylectomy of the axis was performed by the transoral approach. The local recurrence of the tumor was found 3 months later and the patient refused further therapy.

Conclusion: Primary giant cell tumor of the axis is a rare type tumor with poor prognosis. Definitive diagnosis should be based on histopathological morphology and surgical treatment should be performed as soon as possible.

\section{Introduction}

Giant cell tumor (GCT) is an aggressive benign lesion with malignant potential. In all giant cell tumors, $75 \%-90 \%$ are involved in the long bone ${ }^{1}$. Spinal involvement of giant cell tumor is relatively rare. It was reported that only $1.4-9.4 \%$ of GCT are found in the spine ${ }^{2}$.To the best of our knowledge, there are few reports describing GCT localized in the axis. The extreme rarity of such an occurrence prompted us to report this case.

\section{Case Report}

Examination. A 39-year-old previously healthy woman applied to our clinic with neck pain and unstable gait. Examination revealed grade 3/5 weakness in all four limbs, graded sensory loss below $\mathrm{C} 2$ level and hyperreflexia of biceps reflex, triceps reflex, radioperiosteal reflex and knee reflex. Imaging studies were obtained, which included plain film, magnetic resonance imaging (MRI) and $3 \mathrm{~d}$ reconstruction of computed tomography (Figure.1). These studies demonstrated an expansive bony mass destruction of the axis vertebral body and odontoid. None of the examinations revealed a different primary tumor site.

Operation. The biopsy of the bony mass on the axis was firstly performed through the transoral approach. The tissue specimen was sent to the Development of the Pathology Medicine at our institution and pathological diagnosis was giant cell tumor of bone, grade II. Two weeks later, occipitocervical fusion by the posterior approach was performed. The location of C1 and C2 were identified by C-arm. Vertebral plate of $\mathrm{C} 2$ to $\mathrm{C} 4$, posterior arch of $\mathrm{C} 1$ and occipital protuberance were exposed layer by layer. After fixation of lateral mass screws in $\mathrm{C} 2-\mathrm{C} 4$ and occipital plate in occipital protuberance, the rod was secured to the occipital plate and lateral mass screws. A notched bone graft from ilium was placed under the rod between occipital bone and spinous process of $\mathrm{C} 2$. Seventeen days after the operation, the patient returned to the operating room to perform $\mathrm{C} 2$ tumor extirpation. C2 vertebral body exposure was obtained 
through the previous transoral approach incision. The tumor was separated and resected subtotally because of the special location of the tumor and serious haemorrhage. After hemostasis, the patient was transferred to the surgical intensive care unit.

Pathological Findings. Histological giant cell tumor shows increased cellularity, with numerous multinucleated giant cells uniformly dispersed among a large population of mononuclear cells. The multinucleated cell population exhibits a large volume and their centered nuclei may contain more than a hundred nuclei. The cytoplasm of the giant cell is abundant. Mononuclear cells are round, oval, polygonal and even spindled which exhibit little cytoplasm. There is little intercellular substrate other than a few collagen. Thus, the final clinicopathological diagnosis of a giant cell tumor of the axis was established. (Figure.2)

Postoperative Course and Treatment. A thorough imaging evaluation was performed consisting of plain film and MRI after occipitocervical fusion (Figure.3). We recommended adjuvant radiation therapy following resection but the patient refused. In follow-up 6 months post-surgery, the patient was able to walk without assistance with impaired sensation, but MRI revealed local recurrence of the tumor (Figure.4). She refused further therapy.

\section{Discussion}

Giant cell tumor of bone is a true neoplastic process originating from the undifferentiated mesenchymal cells of the bone marrow ${ }^{3}$. Giant cell tumor of bone is generally considered benign, but they also been associated with malignant characteristics such as local recurrence and lung metastasis. Giant cell tumors of spine are rare and frequently develop in females between 10 and 30 years ${ }^{4}$. Tumors in vertebral bodies are difficult to diagnose at the early stage. With the development of imaging techniques such as $\mathrm{MRI}$, the discrepancy between onset of symptoms and diagnosis has been shortened. Although the tumor usually present as a soft tissue density mass with expansion of bone and intact cortex on CT scan, this finding is not exclusive to this lesion and the diagnosis is established only on the basis of a biopsy ${ }^{5}$.

Management of giant cell tumor in the axis is complex. Because of the rarity of these vertebral body tumors, there is no known guidance in literature in this situation. The primary treatment of choice for these lesions is complete surgical removal. The anterior approach gives a direct exposure to the axis tumor. There are two techniques for an anterior approach to the upper cervical spine. One technique is the anterior transpharyngeal approach, as represented by the transoral approach. Transoral approach provides direct exposure for axis tumor, but has disadvantages of limited operative field and risk of infection. The second anterior approach to the upper cervical spine is the extrapharyngeal approach, involving the anterolateral approach and the transcervical approach. These approaches permit wide exposure to the complete tumor and its surrounding structures. However, these procedures may cause aggravation of the neurologic symptoms due to neck must be rather strongly rotated or extended to explore the upper cervical spine. A posterior stabilization often is often required to stabilize the spine after anterior decompression. C1-C4 fixation is the method of choice for posterior fixation. Bone defects 
caused by removal of the odontoid can cause cervical instability. Singh used a modified iliac crest graft with mesh cage as plate to reconstruction of $\mathrm{C} 2$ vertebral body combined with posterior fixation achieving a good result ${ }^{6}$.

The preferred treatment of most giant cell tumor is surgery, but most GCT in the axis is more difficult to totally resect for its location in proximity to the neurovascular structures and has a higher rate of recurrence. The recurrence rate of GCT in En-bloc excision cases was 7.7\%, whereas the recurrence rate in subtotal excision cases was $61.3 \%{ }^{7}$. Adjunctive therapies such as radiation and anti-receptor activator of nuclear factor-kappaB ligand antibodies are recommended to reduce the risk of recurrence if total removal cannot be performed ${ }^{8}$. In this case, our primary goal is to stabilize the spine because the patient existing atlantoaxial dislocation. The treatment we chose to apply was posterior occipitocervical fusion followed by focus clearance through mouth. After stable surgery, the patient's neurological function was significantly restored. But complete surgical excision was not obtained due to the special location of the tumor in the axis and significant blood loss from the tumor. The recurrence of the tumor was found at 3 months follow-up and the patient refused further treatment.

In conclusion, the axis is an extremely uncommon site for the occurrence of a giant cell tumor. Early diagnosis and wide excision are recommended for giant cell tumors of the axis. An incomplete excision is associated with a high incidence of recurrence.

\section{Abbreviations}

GCT: Giant cell tumor; CT: computed tomography; MRI: magnetic resonance imaging

\section{Declarations}

\section{Availability of data and materials}

The dataset supporting the findings and conclusions of this case report is included within this article.

\section{Acknowledgements}

The authous acknowledge our patient for allowing for her case to be presented.

\section{Informed consent statement}

Informed consent was obtained from the patient.

\section{Written informed consent}

Patient has provided informed consent for publication of the case.

\section{Conflict of interest starement}


The authors declare that there is no conflict of interest related to this report.

\section{Ethical statement}

An approved written informed consent was obtained from the patient and his family. Ethical approval was obtained from the Ethics Committee of the First Affiliated Hospital of Shandong First Medical University, in accordance with the ethical guidelines of the 1975 Declaration of Helsinki.

\section{Author's contributions}

Peng Wang and Chunhao Song drafted the manuscript. Xiangquan Chu provided clinical information. Cong Chen and Bo Liu performed the interpretation of the histologic features and imaging results

\section{Funding}

Not applicable

\section{References}

1. Leonard J, Gokden M, Kyriakos M, Derdeyn CP, Rich KM. Malignant giant-cell tumor of the parietal bone: case report and review of the literature. Neurosurgery. 2001;48(2):424-429.

2. Boriani S, Cecchinato R, Cuzzocrea F, Bandiera S, Gambarotti M, Gasbarrini A. Denosumab in the treatment of giant cell tumor of the spine. Preliminary report, review of the literature and protocol proposal. Eur Spine J. 2020;29(2):257-271.

3. Szendroi M. Giant-cell tumour of bone. J Bone Joint Surg Br. 2004;86(1):5-12.

4. Sanjay BK, Sim FH, Unni KK, McLeod RA, Klassen RA. Giant-cell tumours of the spine. J Bone Joint Surg Br. 1993;75(1):148-154.

5. Lee HJ, Lum C. Giant-cell tumor of the skull base. Neuroradiology. 1999;41(4):305-307.

6. Singh PK, Agrawal M, Mishra S, et al. Management of C2 Body Giant Cell Tumor by Innovatively Fashioned Iliac Crest Graft and Modified Cervical Mesh Cage Used as Plate. World Neurosurg. 2020;140:241-246.

7. Yin $\mathrm{H}$, Yang $\mathrm{X}, \mathrm{Xu} \mathrm{W}$, et al. Treatment and outcome of primary aggressive giant cell tumor in the spine. Eur Spine J. 2015;24(8):1747-1753.

8. Yamamoto H, Ishihara S, Toda Y, Oda Y. Histone H3.3 mutation in giant cell tumor of bone: an update in pathology. Med Mol Morphol. 2020;53(1):1-6.

\section{Figures}




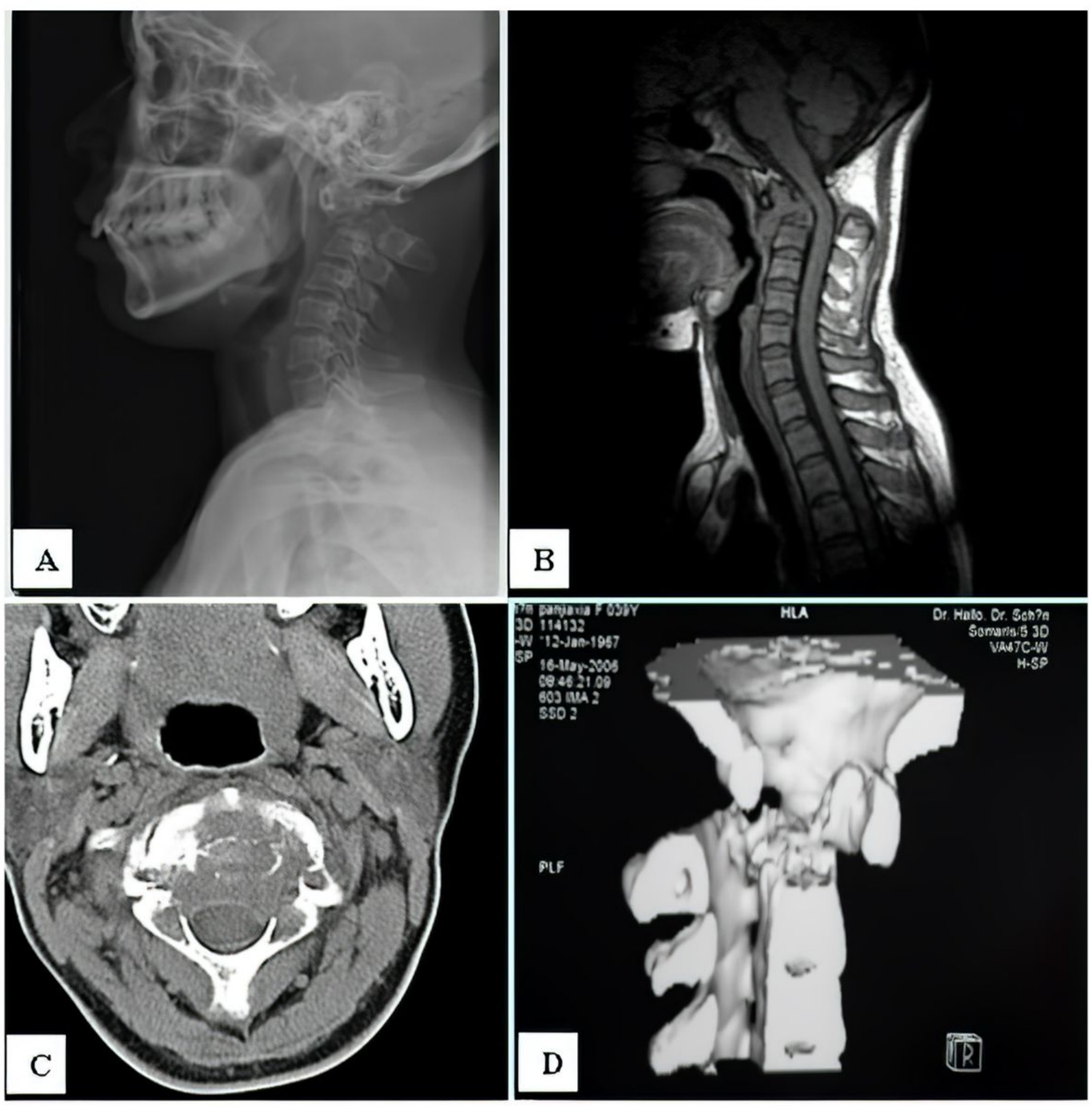

Figure 1

Preoperative imaging giant cell tumor of the axis. X-ray (A), MRI (B), CT scan (C) and 3D reconstruction (D) showed that the tumor was centered on the $\mathrm{C} 2$ vertebral body and involved the odontoid and the atlas. 


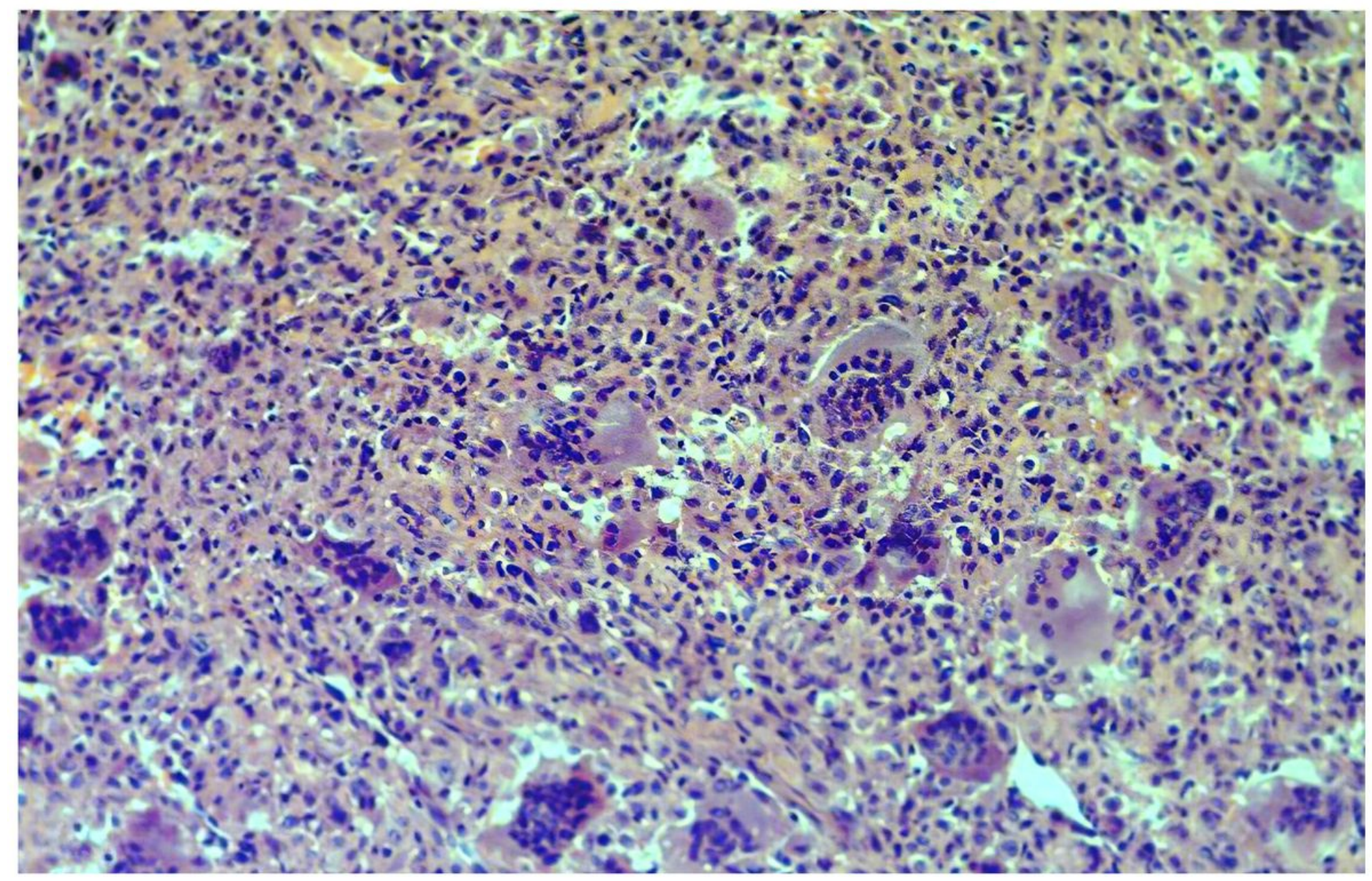

\section{Figure 2}

Histological appearance of the giant cell tumor showing hypercellularity with a population of mononuclear cells and numerous giant multinucleated cells uniformly dispersed. (HE staining $\times 200$ ) 


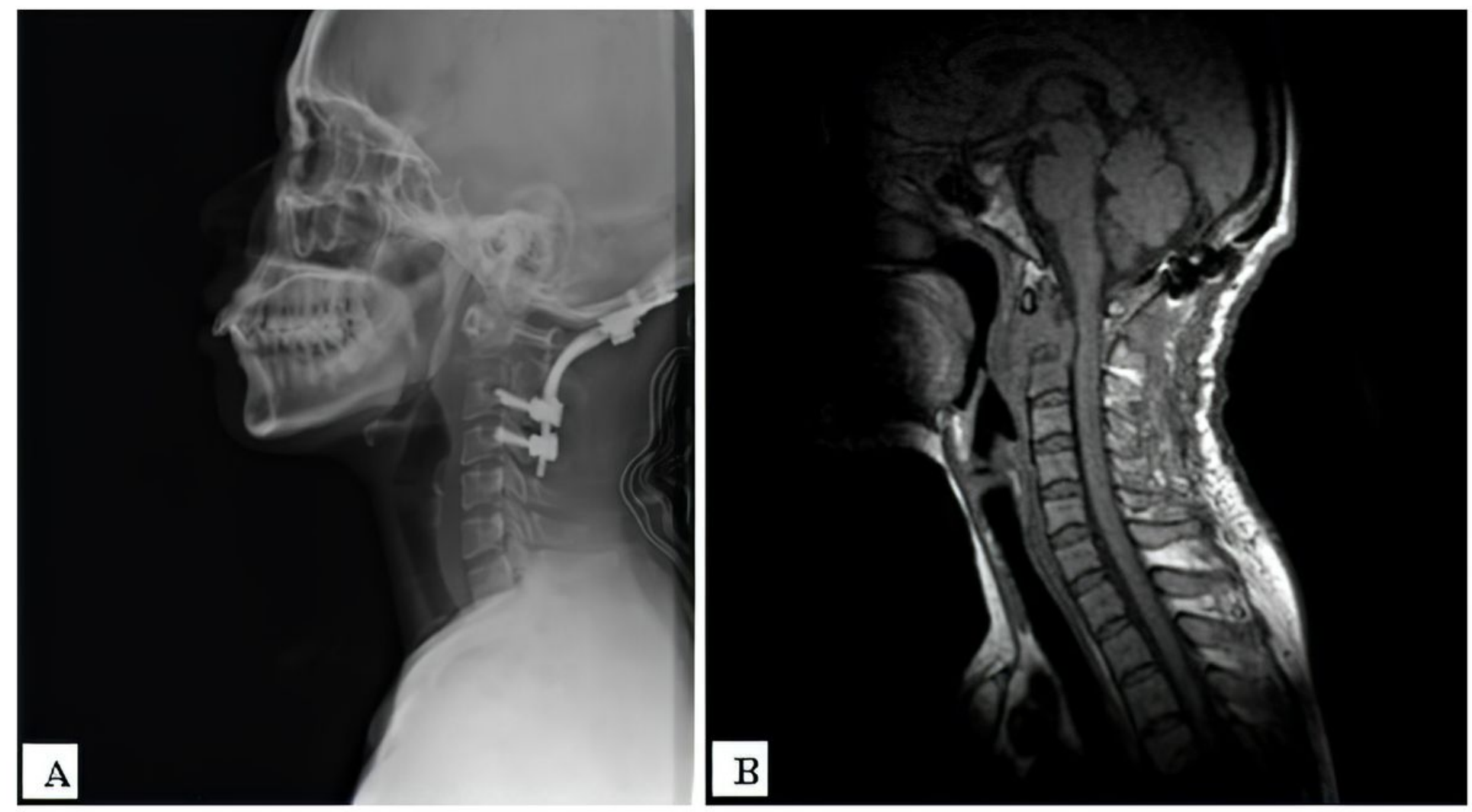

Figure 3

Postoperative lateral X-ray (A) and CT scan (B) after occipitocervical fusion. 


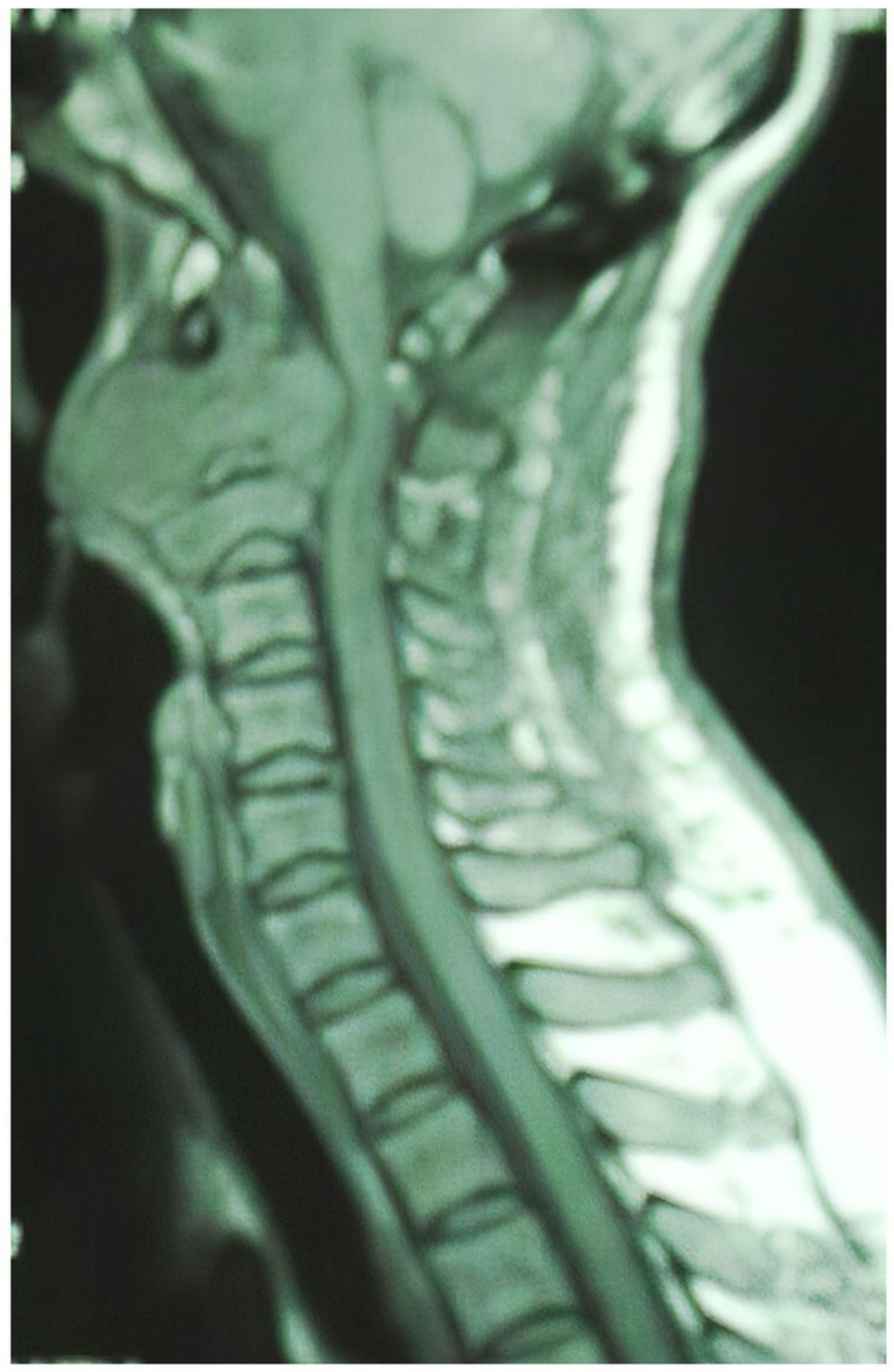

Figure 4

MRI shows the recurence of the tumor at 3 months follow-up.

\section{Supplementary Files}

This is a list of supplementary files associated with this preprint. Click to download. 
- CAREchecklistEnglish2013.pdf

Page 10/10 